\title{
ASO Visual Abstract: Current Surgical Management of Inflammatory Breast Cancer
}

\section{T. Adesoye, MD, MPH ${ }^{1}$, and A. Lucci, MD, FACS ${ }^{1,2}$}

${ }^{1}$ Department of Breast Surgical Oncology, The University of Texas MD Anderson Cancer Center, Houston, TX;

${ }^{2}$ Department of Breast Surgical Oncology, Morgan Welch Inflammatory Breast Cancer Research Program and Clinic, The University of Texas MD Anderson Cancer Center, Houston, TX

In our article, we discuss the available evidence and controversies in the current surgical management of patients with inflammatory breast cancer (IBC) (https://doi. org/10.1245/s10434-021-10522-z).

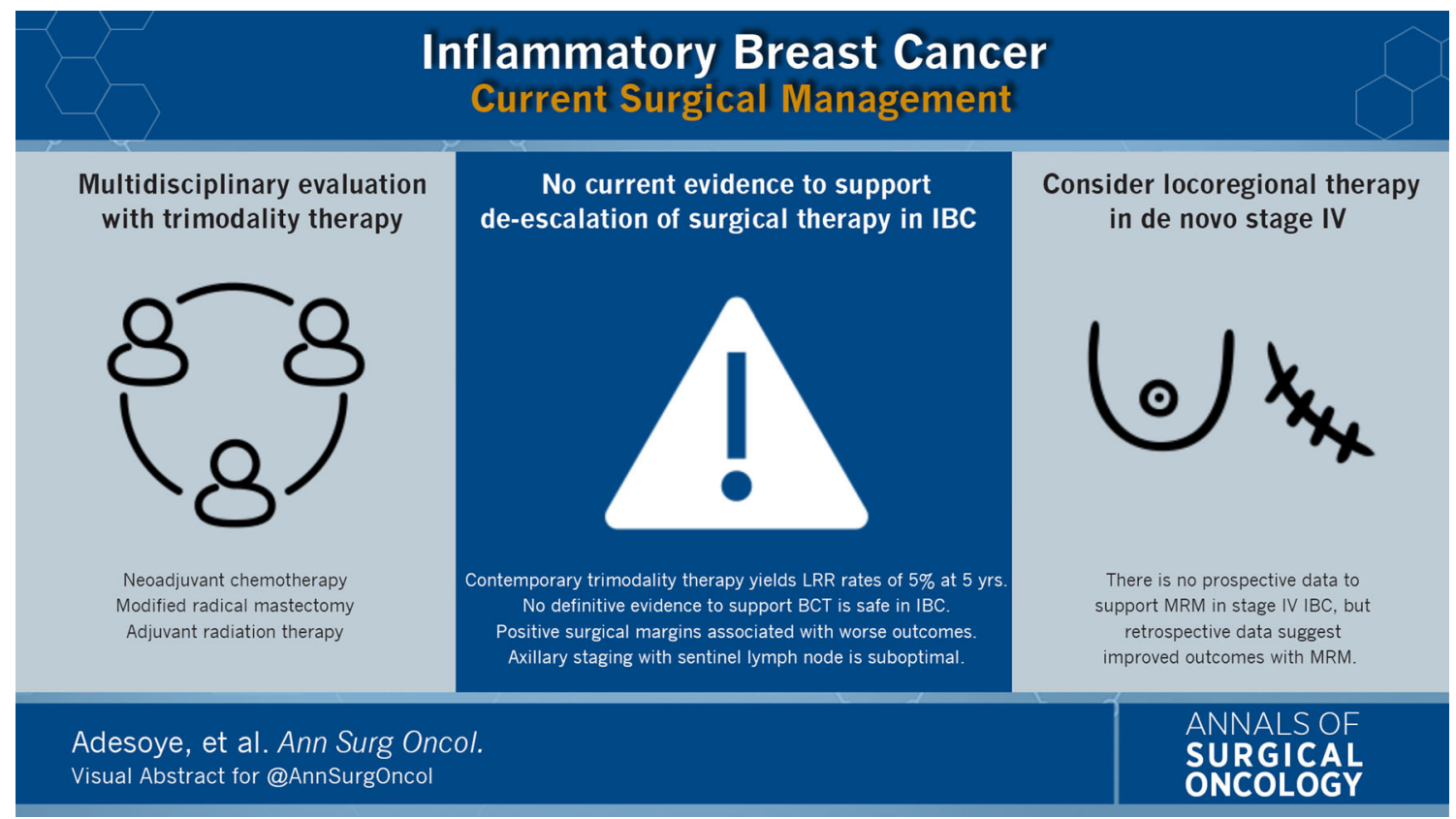

(C) Society of Surgical Oncology 2021

Published Online: 13 August 2021

A. Lucci, MD, FACS

e-mail: alucci@mdanderson.org
ACKNOWLEDGEMENTS Institutional database supported by Morgan Welch Inflammatory Breast Cancer Research Program, and State of Texas Rare and Aggressive Breast Cancer Research Program Grant.

\section{DISCLOSURES None.}

Publisher's Note Springer Nature remains neutral with regard to jurisdictional claims in published maps and institutional affiliations. 